\title{
The adverse effects of obesity on reproduction
}

\author{
Jane E Norman \\ Centre for Reproductive Biology, University of Edinburgh, 47 Little France Crescent, Edinburgh EH16 4TY, UK
}

Correspondence should be addressed to J E Norman; Email: jane.norman@ed.ac.uk

Obesity (defined as a body mass index (BMI) of $\geq 30 \mathrm{~kg} / \mathrm{m}^{2}$ ) is perhaps the major health challenge facing resource-rich countries. Obesity is a major cause of ill health and mortality in countries where it is prevalent, largely via increased rates of ischaemic heart disease, stroke, diabetes, hypertension and osteoarthritis, with cancer (particularly colon and breast) also playing a role (Haslam \& James 2005).

The current prevalence of obesity in the UK is around $20 \%$, somewhat behind that of the USA at $34 \%$ (Flegal et al. 2010), but rates are rapidly increasing in both countries. The Foresight report, commissioned by the UK government, indicated that in the absence of substantial intervention, rates of obesity would continue to increase in the UK to around $50 \%$ in the adult population by 2050 , with the annual NHS costs of obesity projected to be $£ 10$ billion by 2050 , and societal costs to be $£ 49$ billion by 2050 (Government Office for Science 2007).

In contrast to its effects on other areas of health, the impact of obesity on reproduction has received less attention. In this focus issue, we review both the influence of obesity on reproductive performance and the current knowledge of mechanisms by which obesity exerts its adverse effects. Understanding these issues should allow targeted therapies to be developed to improve reproductive health between the obese and their offspring.

Perhaps the most well-established connection between obesity and reproductive problems is the link between obesity and infertility, as reviewed by Brewer \& Balen (2010). Obesity decreases successful pregnancy rates in both natural and assisted conception cycles, with fertility being partially restored if weight loss can be achieved. The mechanism(s) by which obesity reduces pregnancy rates are complex and likely multifactorial. Insulin resistance appears to be a key factor to obesityinduced anovulation, with high levels of insulin leading to low levels of sex hormone-binding globulin, hyperandrogenaemia and high levels of free insulin-like growth factor 1 . The loss of as little as $5 \%$ of body weight is accompanied by an increase in ovulation rates and reduces biochemical abnormalities. Elevated levels of leptin and low levels of adiponectin have also been implicated in the mechanism by which obesity reduces conception rates, but there is much less information on their role.

Over and above a decrease in ovulation rates, obesity also increases the rate of miscarriage, thus further decreasing successful pregnancy rates among obese women. Potential mechanisms include poorer quality oocytes and/or a defect in endometrial receptivity - with insulin resistance again implicated in the latter event.

Given the above, it is not surprising that success rates of assisted reproductive technologies are lower in obese individuals. These data have led the British Fertility Society to recommend 'Women who are obese must initiate a weight reduction programme and those severely overweight (defined as having a BMI of 36 or more) should not receive treatment until their weight has reduced' (Kennedy et al. 2006).

In contrast to these effects on female fecundity, there is much less evidence that obesity adversely affects male fertility. Although obese men have lower total and free testosterone levels, meta-analyses have so far failed to confirm an effect of obesity on semen parameters, indicating that if obesity does reduce male fertility then the effect is likely to be subtle (MacDonald et al. 2010).

Once obese women are pregnant, their risk of pregnancy complications is significantly greater than their lean counterparts. As reviewed by Catalano (2010) in this issue, many of the adverse outcomes of obesity (including gestational diabetes and pre-eclampsia) occur as a result of increased insulin resistance. Even lean pregnant women are insulin resistant compared to their non-pregnant counterparts, with insulin resistance mediated downstream of the insulin receptor by defects in SLC2A4 (GLUT4) mobilisation. It is likely that this is induced by circulating factors, with cytokines such as tumour necrosis factor- $\alpha$ among the leading candidates.

Denison et al. (2010) review the contribution of adipose tissue and the placenta to the biology of obese pregnant women. There is a clear link between adipose tissue invasion of $\mathrm{T}$ cells and macrophages, increased circulating cytokines of adipose tissue origin and insulin resistance in non-pregnant individuals but less information on whether this also occurs in pregnancy. The placenta likely plays a key role - with an emerging hypothesis that the placenta can 'sense' the metabolic 
environment and alter its function accordingly: whether these alterations are beneficial or harmful for the baby's health is still to be determined.

The increased insulin resistance in obese pregnant women leads not only to pregnancy complications for the mother, but also greater growth and disproportionally greater fat mass for the baby. Thus, high pre-pregnancy and early pregnancy BMI predisposes to the birth of an overweight baby. As reviewed by Drake \& Reynolds (2010) in this Focus Issue, these overweight babies are themselves more likely to be obese as adults, and to have disordered glucose metabolism, vascular function and hypertension: the 'developmental overnutrition' hypothesis. This transmission of obesity from generation to generation appears restricted to mothers, with paternal obesity having little effect. If this is true, it suggests that the in utero environment may be the key mediator to the maternal-offspring transmission of obesity. Again, this is an area of much research. Likely biological pathways include the effects of maternal obesity in 'programming' offspring appetite, activity levels, and muscle and adipose tissue composition. Such studies need careful controls, but most human (and animal) studies have not previously distinguished the effects of maternal obesity from the effects of offspring overnutrition.

The obvious question is whether any therapies can be introduced to treat this vicious cycle. The Institute of Medicine in the USA now recommends that obese pregnant women limit weight gain during pregnancy (Rasmussen et al. 2009), but there is minimal evidence supporting intensive lifestyle interventions (improved diet and exercise) during pregnancy. As Catalano (2010) states, lifestyle interventions are most likely to be effective if applied early in pregnancy or (ideally) prior to conception in women who are planning to become pregnant.

Given that insulin resistance appears to be the key factor to many of the adverse consequences of obesity in pregnant women, therapies designed to improve insulin sensitivity in pregnancy could be effective. We are currently conducting a National Institute of Health Research Efficacy and Mechanisms Programme-managed, Medical Research Council-funded double-blind placebocontrolled study to determine the effect of the insulinsensitising agent metformin on birth weight centile in obese pregnant women (EMPOWAR, ISRCTN51279843), which we hope will begin to address this issue.

The last paper in this Focus Issue (Burt Solorzano \& McCartney 2010) discusses the effect that obesity has on the pubertal transition: advancing it in girls and delaying it in boys. The secular trend towards an earlier age of puberty in girls is well known, but it is not clear whether this is a cause or an effect of the increased prevalence of obesity in children, or whether both have common, as yet unidentified factors. Burt Solorzano \& McCartney (2010) again review the mechanisms by which obesity modifies puberty, with leptin and insulin again appearing to be key candidates in this process.
We hope that these reviews will summarise the available evidence around the adverse effects that obesity has on reproduction. The Foresight report, commissioned by the UK government, indicated that the 'prevalence of obesity is a major challenge, not just for medicine and public health but for governance and decision making' (Government Office for Science 2007). As we have shown, this challenge will require input, not only from those working in the fields of public health, cardiovascular disease and cancer, but also from reproductive biologists, obstetricians and gynaecologists. The ultimate hope is a 'cure' for obesity, but achieving such an aspiration is a long way off. The National Institute for Clinical Excellence (NICE) recommends lifestyle interventions, which encourage a nutritionally balanced diet with appropriate calorie content and which promote the benefits of regular exercise for individuals with a BMI $\geq 25$, the drug orlistat for those with a BMI $\geq 30$ and bariatric surgery for those with a BMI of $>50$ (National Institute for Health and Clinical Excellence 2006); but there is little evidence that these recommendations are making an impact on the prevalence of obesity in the population. Thus, it is likely that the 'challenge' of obesity will remain for reproductive biologists for some time to come.

\section{Declaration of interest}

The authors declare that there is no conflict of interest that could be perceived as prejudicing the impartiality of the research reported.

\section{Funding}

The author receives grants from Tommy's and from UK governmental institutions to conduct research into understanding and preventing the adverse effects of obesity in pregnancy.

\section{References}

Brewer CJ \& Balen AH 2010 The adverse effects of obesity on conception and implantation. Reproduction 140 347-364. (doi:10.1530/REP-09-0568)

Burt Solorzano CM \& McCartney CR 2010 Obesity and the pubertal transition in girls and boys. Reproduction 140 399-410. (doi:10.1530/REP-10-0119)

Catalano PM 2010 Obesity, insulin resistance, and pregnancy outcome. Reproduction 140 365-371. (doi:10.1530/REP-10-0088)

Denison FC, Roberts KA, Barr SM \& Norman JE 2010 Obesity, pregnancy, inflammation, and vascular function. Reproduction 140 373-385. (doi:10.1530/REP-10-0074)

Drake AJ \& Reynolds RM 2010 Impact of maternal obesity on offspring obesity and cardiometabolic disease risk. Reproduction 140 387-398. (doi:10.1530/REP-10-0077)

Flegal KM, Carroll MD, Ogden CL \& Curtin LR 2010 Prevalence and trends in obesity among US adults, 1999-2008. Journal of the American Medical Association 303 235-241. (doi:10.1001/jama.2009.2014)

Government Office for Science 2007 Foresight - Tackling Obesities: Future Choices - Project Report, edn 2. London: Government Office for Science. Available at http://www.foresight.gov.uk/obesity/17.pdf. 
Haslam DW \& James WP 2005 Obesity. Lancet 366 1197-1209. (doi:10. 1016/S0140-6736(05)67483-1)

Kennedy R, Kingsland C, Rutherford A, Hamilton M \& Ledger W 2006 Implementation of the NICE guideline - recommendations from the British Fertility Society for national criteria for NHS funding of assisted conception. Human Fertility 9 181-189. (doi:10.1080/ 14647270600908411)

MacDonald AA, Herbison GP, Showell M \& Farquhar CM 2010 The impact of body mass index on semen parameters and reproductive hormones in human males: a systematic review with meta-analysis. Human Reproduction Update 16 293-311. (doi:10.1093/humupd/dmp047)
National Institute for Health and Clinical Excellence 2006 Clinical guideline 43. In Obesity: Guidance on the Prevention, Identification, Assessment and Management of Overweight and Obesity in Adults and Children. London: National Institute for Clinical Excellence. Available at http://www.nice.org.uk/guidance/CG43.

Rasmussen KM, Yaktine AL \& Institute of Medicine (US) Committee to Reexamine IOM Pregnancy Weight Guidelines 2009 Weight Gain During Pregnancy: Reexamining the Guidelines. Eds KM Rasmussen \& AL Yaktine. Washington, DC: National Academies Press. Available at http://www.iom.edu/Reports/2009/Weight-Gain-During-PregnancyReexamining-the-Guidelines.aspx. 